\title{
Feeling the Right Personality. Recruitment Consultants' Affective Decision Making in Interviews With Employee Candidates
}

\section{Taina Kinnunen'}

University Lecturer of Cultural Anthropology, University of Eastern Finland Joensuu Campus, P.O. Box 111, FI-80101 Joensuu, Finland

I Jaana Parviainen

Senior Researcher, School of Social Sciences and Humanities, FI-33014

University of Tampere, Finland

\begin{abstract}
The pressure to find the 'right' personalities to strengthen customer service and working teams has made staffing decisions critical for organizations. Therefore, recruitment is more often outsourced and done so on a global level. By analyzing interviews with recruitment consultants, this article explores how consultants work in order to find the recruitment candidates with the most potential for their clients. It discusses recruitment as a process of affective decision-making where consultants use their 'gut feelings', that is, their own embodied affects, to secure the optimal 'organizationperson fit'. Different kinds of details in the candidate's appearance and micro-movements of the body cause 'good vibrations' or 'strange feelings' in the consultant's affective body, which guides the selection among the candidates. By deconstructing the concept of 'affect', the article develops an understanding of recruitment as a practice where the embodied histories of consultants themselves play a key role in recruitment. The article claims that, as a result of competition in the business, the recruitment consultant relies on stereotypical performances of the ideal worker.
\end{abstract}

\section{KEY WORDS}

Affective decision-making / affects / gut feelings / labor market / recruitment / recruitment consultants

DOI

10.19154/njwls.v6i3.5525

\section{Introduction}

t's a gut feeling ... so I don't necessarily have to interview so much. I see really quickly in the interview what kind of personality the guy has ... when he walks in, how he behaves, shakes hands and so on. (Timo, a male consultant)

Together with headhunters, recruitment consultants are gatekeepers for the labor market, whose business rests on their ability to deploy 'fitting' personalities in specific organizational cultures with core aims and values, performance norms, communicational

\footnotetext{
${ }^{1}$ E-mail: taina.kinnunen@uef.fi
} 
customs, routines, symbols, and emotional etiquettes (cf. Downey et al., 2011; Finlay \& Coverdill, 2000; Gardner et al., 2012; Tienari et al., 2013). Depending on the contract with the client company, consultants either utilize their own databases or announce vacancies in a wide range of media to find their potential recruits. After receiving applications, the final list of potential recruits is assembled by determining which candidates fulfill the formal criteria of education, work experience, or other specific skills. References may also be requested and facts on the CVs may be checked. Some clients also reveal their prerequisites in terms of the recruited employee's age, gender, and ethnicity, although open discussion of these 'taboo' issues is normally avoided (also Koivunen et al., 2015).

Many studies have implied that the body has a central role in recruitment criteria (e.g., Adkins, 1992; Caven et al., 2013; Meriläinen et al., 2013; Nickson et al., 2003; Tipper, 2004). Informal discrimination concerning bodies of different ages, ethnicities, and genders, in particular, has been analyzed by several researchers (e.g., Combs et al., 2012; Dean, 2005; Kadefors \& Hanse, 2012; Loretto \& White, 2006; Nilsson, 2011; Tienari et al., 2013). However, discussion of recruitment criteria applied in recruitment interviews is scarce (Meriläinen et al., 2013). In any event, we know that the employers look for labor processes that are based on embodied capacities or attributes possessed by workers since managerial strategies aim to maximize customer satisfaction (Nickson et al., 2001, p. 170). 'Looking good' and 'sounding right' not only contribute to the matrix of skills demanded by employers but also function to materialize an organization's style or brand. However, too little is still known about how recruitment staff make their judgments of job applicants' embodied capabilities, such as 'person-to-person' skills in the new 'style-labor market' (Nickson et al., 2003). In particular, the existing literature does not say much about the embodied labor of recruitment consultants themselves and how it is intertwined with their recruitment criteria (Humle, 2014; Meriläinen et al., 2013).

In order to meet the expectations of their client companies, recruitment agencies have developed different evaluation methods to test candidate personality traits, abilities, and competencies (e.g., Downey et al., 2011; Gardner et al., 2012). Nevertheless, employees are seldom selected by mere CVs and standardized tests. One consultant said that psychological tests can only 'smell outlines' of different personalities and should only serve as a 'basis for discussion'. In the second phase of the recruitment process, which this article addresses, consultants rely on their '(gut) feelings', 'intuition', and 'first impressions' in assessing the personality of candidates, as the 10 Finnish recruitment consultants interviewed for this article described. Consultants clearly talked about the affects that different kinds of candidate appearances and behaviors generate in them. But how are those affects utilized precisely; what kinds of decisions are made on the basis of them? What do consultants actually mean by 'impression of personality'; what kinds of embodied appearances and gestures do they pay attention to?

This article discusses the employee selection process as a form of organizational decision-making activity. Specifically, our purpose is to develop the notion of 'affective decision making' (ADM, e.g., Bracha \& Brown, 2009; Daniels, 2008) in the context of assessing the job-seekers' personality in recruitment interviews. We will address how consultants reflect their embodied affects throughout the recruitment process to 1) understand the expectations and needs of their client companies and 2) select the 'best' employee candidates for them. We argue that ADM helps us to make sense of the 
way our interviewees characterized their work as relying on 'gut feeling' and described it as the core of their professional skills (cf. Bailly \& Léné, 2013, pp. 88-89; Tienari et al., 2013, p. 55). In developing the concept of ADM, we build on and bridge our work over organizational theories of decision making (e.g., Dane \& Pratt, 2007; Hodgkinson $\&$ Starbuck, 2008). We further extend our theoretical elaboration to the research of affects because these are inter-corporeal and relational (e.g., Seyfert, 2012) and can only be understood in their embodied socio-cultural context, as many affect theorists have argued (e.g., Ahmed 2004; Wetherell, 2012). Therefore, we suggest that it is inevitable that we ask what kinds of bodies encounter each other in the recruitment interview (cf. Coole, 2007).

Before introducing our theoretical approach to affects in decision making, we first present our research material and methodology. We will then proceed by discussing consultants' work as 'puzzle solving': matching specific working environments and teams with suitable personalities. Next, we will concentrate on the consultants' descriptions of their typical interviews with candidates. We will identify the job applicant's multisensory, bodily 'messages' that matter in the recruitment review: which details in appearance and bodily gestures cause 'good vibrations' or 'strange feelings' in the consultants. We will conclude by discussing how the recruitment consultants' decision making is based on calculating the satisfaction of clients, which results in a search for 'risk-free bodies'.

\section{Research material and methodology}

The article is based on interviews with 10 recruitment consultants representing three well-known recruitment companies in Finland; these interviews were conducted in the year 2013. The interviewees, whom we call 'consultants', bore the job titles Recruitment Consultant, Personnel Consultant, or HR Consultant. Three of them occupied management positions, working as a team leader, regional manager, or head of the department in their respective company, and two of them were specialized in the formal, psychological assessment of job seekers. Six of the interviewees were female and four were male, all presumably in their 30s or 40s. They are identified by nicknames in the text.

The representativeness of and number of interviewees were carefully designed. We looked for interviewees who had done consulting work in the information and communication technology (ICT) sector. ${ }^{1}$ Although outsourcing direct recruitment has been most common in the ICT sector in Finland (Junnila \& Honkaniemi, 2010), the total volume of the recruitment consulting business is limited in a small country with a downturn in economy. There are no recruitment companies specialized solely in ICT; their client organizations cover several employer sectors. In any event, our interviewees had consulted in the ICT field either principally or among other industries from one to several years in one or several companies. The discussion in this article thus concerns not only the ICT sector but also recruitment consulting practices on a more general level.

The interviewees were located by first informing the principal chiefs of the companies about our study through e-mail and requesting contact information for potential interviewees. Subsequently, we called the interviewees and made appointments in their offices. Consultant schedules are tight, and usually the interviewees proposed a limited time frame for the appointments. The interviews lasted 70 minutes on average, 
and they all were recorded and transcribed verbatim. We found it suitable to our purposes to limit the number of interviewees to 10 . First, finding a large number of interviewees who met our criteria would have been challenging-some of the contacted persons had politely declined to participate in the study. After all, our purpose was neither to make statistical generalizations nor systematically test differences among groups. Instead, we aimed at gaining in-depth knowledge of a specific theme and interpreting it in detail in a given theoretical and socio-cultural context (cf. Kvale, 1996, pp. 101-103). However, the point of saturation was reached during the interviews, that is, we became convinced that additional interviews would not have been of significant additional benefit to our study.

Our theoretical hypothesis was that various kinds of person-to-person skills (Nickson et al., 2003) are emphasized even in businesses more traditionally based on tangible technical skills, such as ICT. This was explained in our informational letter to the companies. The interview questions were sent beforehand to the interviewees. The focus of the interviews was to find out how emotional, esthetic, and social competencies are embodied, according to the consultants. This theoretical question was operationalized into interview questions examining how consultants decide between different candidates: what kind of behaviors, gestures, and appearances they pay attention to in the recruitment interview. The interviews began with questions about typical assignments and recruitment processes in order to understand the frames and phases of their decision making. We also discussed the consultants' career histories and how they had gained their working skills. Of special interest were the practices of their work: how they determine who the 'good guy'/'right guy' is.

As we had anticipated, the interviewees found it challenging to concretize their working methods and selection criteria. Therefore, our interviews combined structure with flexibility and were dialogic by nature. We adopted techniques of 'active interviewing' (Holstein \& Gubrium, 1997, p. 123) that are typical for in-depth interviews (Legard et al., 2003, pp. 138-142) in order to help the consultants to describe their ideas, feelings, and reactions in their everyday work (cf. Kinnunen, 2010, p. 260). In order to generate new knowledge about a vaguely explored subject and to obtain deep understanding of the interviewee's views, purposeful follow-up questions during the discussion are very important (Legard et al., 2003, p. 141). The discussions of key themes with our interviewees were initiated using open questions; subsequently, hiring scenarios were presented which related to applicants' bodily attributes (e.g., behavior, appearance, clothing, etc.) to clarify our tentative ideas about the virtues of the 'new working body'. We also reflected our own experiences and even utilized humor and provocation in order to achieve the depth of answers.

Further, four of the 10 interviews were conducted with two researchers present to make sure that all relevant details and hints in the discussions were collected for further development of the course of the interview. Regarding the interviewees' answers, we did not note any marked difference between these and those generated by other interviews that either of the researchers conducted alone. It must be noted that consultants are professional interviewers themselves and trained in conducting discussions with different kinds of people in their daily work. Some of the interviewees expressed their suspicion that we, as researchers, could be interested in catching their companies practicing discrimination. After ethical research principles-for example, respecting the interviewees' views as such and guaranteeing their anonymity-were discussed, we felt that the 
atmosphere in all interviews was relaxed and confidential. All interviewees also acted in a very friendly manner toward us.

The analysis of the interviews followed the principles of content analysis, which aims to 'attain a condensed and broad description of the phenomenon, and the outcome of the analysis is concepts or categories describing the phenomenon' (Elo \& Köngäs, 2008, p. 108). Both deductive and inductive-or 'directed' and 'conventional,' as Hsieh and Shannon (2005) call these-analysis methods were conducted. The directed analysis concerned the issue of embodiment of the ideal working body in a recruitment interview in particular. The existing research and our theoretical framework guided us to start coding the material that in some way dealt with those details of the applicants' appearance and behavior that the consultants assumed indicate the applicants' social skills and personalities. Next, we categorized which of these attributes generate positive or negative feelings or 'vibrations' in the consultants and how they explained them. The working methods and competences of the consultants slightly surprised us, which led us to read all interview phrases describing them very carefully to discover heuristic theoretical concepts that could explain the data. First, we realized that 'intuition' and 'gut feeling' can be used both as 'emic' and 'etic' concepts; we decided to apply them as theoretical concepts in our own analysis as well (Headland et al., 1990). The inductive (conventional) approach thus permeated this phase of content analysis, finally inspiring us to interpret all relevant material once again from the perspective of ADM and affects.

\section{Theoretical framework:Affects in decision making}

As we claim that the consultants' judgments of job candidates operate through affective resonances and meaning-makings in their bodies, it is necessary to note how affects have been discussed in the context of intuition and decision making. After that, we will develop the concept of ADM by turning to theories pertaining to embodied affects.

In the theories of decision making, intuition has been viewed as a form of information processing that differs from rational, or analytical, processes (e.g., Agor 1989; Behling \& Eckel, 1991; Khatri \& Ng, 2000). However, as researchers (e.g., Burke \& Miller, 1999; Dane \& Pratt, 2007) note, intuition is not a mystical avenue to reasoning and judgment but rather nonconscious heuristics. In their conceptual analysis of intuition, Dane and Pratt (2007, p. 36) find four characteristics that make up the core of the construct: '...intuition is a (1) non-conscious process (2) involving holistic associations (3) that are produced rapidly, which (4) result in affectively charged judgments.' They suggest that common to both heuristic and expert decision making is the view that individuals nonconsciously make holistic associative connections between the stimuli they encounter and their underlying cognitive structures in the process of intuiting. In analyzing the role of intuition in managerial decision making, they draw a distinction between intuitive processes and outcomes. While the outcomes of intuiting, intuitive judgments are clearly accessible to conscious thinking, how one arrives at them is not. Dane and Pratt further clarify that affects and emotions are an integral component of intuitive judgments. In fact, they find synonyms for intuition in 'gut feelings' or 'gut instincts' (cf. Hayashi, 2001; Shapiro \& Spence, 1997). They come to the conclusion in their conceptual analysis that while promising, research that examines the connection between the body and the use of intuition remains scant. 
A number of authors in organizational decision-making theories have likewise discussed the importance and influence of emotions and affects in the decision-making process (e.g., Daniels, 2008; Lakomski \& Evers, 2010; Sadler-Smith \& Sparrow, 2008; Weick, 1995). In his analysis of the influences of cognition on emotions and moods, Daniels (2008) describes affects as having independent negative and positive dimensions; negative affect varies from relaxation to anger, whereas positive affect varies from boredom to enthusiasm. In the context of economic theories of decision making, Bracha and Brown (2009) have introduced their notion of ADM that refers to an intrapersonal game or struggle between deliberate consideration and emotional processing. They emphasize that ADM is a theory of choice that posits rational and emotional processes as interacting simultaneously and in parallel.

Although the theories of intuitive and organizational decision making do recognize the role of affects in strategic choices and provide useful insights, they lack theoretical approaches that elucidate the central role of the body in the process (cf. Dane \& Pratt, 2007). In particular, they do not deconstruct the concept of affect in relation to the lived body and its socio-cultural context, although some authors have affirmed that decision makers' beliefs and values are associated with and affected by culture (e.g. Hofstede, 1997). Our intention is to re-conceptualize 'affective decision making' in the context of recent multidisciplinary affect theories by defining it as affectively charged judgments that arise through preconscious bodily associations and perceptions in a given embodied encounter and socio-cultural context. 'Affects', in turn, can broadly be defined as subjective, inter-corporeal and at least partly socially adopted corporeal feelings and sensations (cf. Blackmann \& Venn, 2010). In some accounts, the concept of affect refers to unmediated, uncontrolled, and unconscious physical reactions, such as sweating, tears, blushing, chills, and goose pumps, while 'emotion' is understood more as an individually and consciously felt and named, innate and/or culturally constructed, controlled, and performed expression (e.g., Gorton, 2007; Probyn, 2004). Several scholars also use these concepts in interchangeable ways without making a distinction between the two (e.g., Ahmed 2004; Wetherell, 2012).

In our case, we prefer the term affect for its connotation of embodied reflections, inter-corporeal vibrations, and meaning-makings (cf. Seyfert, 2012; Wetherell, 2012). Our attempt is to theorize the way consultants described their working and decision making: feeling, sensing, and knowing without exact words, using their 'gut feeling'. We assume that although affects are experienced by individual bodies and the human body's capacity to feel them is partly innate, they are not pre-social; rather, the social is already embedded in them. Affects are 'informed' by cultural discourses of different bodies, such as verbal and visual representations of ages, genders, classes, sizes, ethnicities, colors, sexualities, and styles, in particular (cf. Kyrölä, 2010, p. 37). Discourses contain socially shared values attached to different kinds of bodies and affective responses that they 'deserve', such as attraction or disgust (cf. Ahmed, 2004). We will address how consultants unconsciously and consciously utilize these discourses in their work when sensing and being exposed to bodily gestures, rhythms, and atmospheres.

As recruitment consultants use their own affective bodies as their working instruments, it is worth noting that affects evolve from the bodies' lived pasts; affects have resonance in bodily remembrance and past experiences (Ahmed, 2004). Therefore, consultants' ADM cannot be separated from their own corporeal histories. It is our intention to show how consultants explicitly and implicitly reflect their own values, passions, 
and interests in their affective judgments. We approach the recruitment interview as an encounter where different 'styles of the flesh' (Coole, 2007) meet, leading to different feelings in the consultants' bodies. In their final decisions, consultants must also rationally process the probable outcomes of their gut feeling, that is, the fit between the interviewed candidates and their paying clients, and hence the success of the assignment.

\section{Results and analysis}

\section{Professional puzzle solvers}

Recruitment consulting is all about puzzle solving: determining what kind of personalities will fit into different working places and teams. In the end, 'it's the chemistry between the client and the candidate that matters', as Seppo explained, and recruitment consultants try to anticipate that chemistry by reflecting their own affects when meeting the employers and the candidates. A typical recruitment process starts from a careful 'specifying' of the open vacancy in order to figure out the goals of the assignment. This includes the consultant's visit to the client company to 'feel the atmosphere', as many interviewees expressed it. The working space itself tells the consultant something, for example, whether each worker has his/her own room or if there is an open office. The spatial design of the organization is a control device for social interaction per se and may produce 'open' or 'closed' scripts for the moving bodies (Hofbauer, 2000). In other words, spatial configurations represent the organization's politics of standardizing the working bodies and amplifying certain affective dynamics between them (Blackmann \& Venn, 2010, p. 20; Halford et al., 1997), which the consultants were clearly aware of.

The closed/open dichotomy correspondingly characterized the way the consultants described coworking cultures and 'typical' team personalities. Tanja explained that it is relevant to pay attention to whether the workers are 'bold' and the working culture is 'a bit loose, not so strict', or if the working environment is 'very quiet, formal and correct'. According to Minna, some teams are 'really rakish and lively and you have to put up with their bad humor,' while others are more 'conservative'. Kaisa explained that the 'style' of some teams is 'open with effervescent personalities', while others' styles are 'just to do your job, go home and be alone'. Different social, spatial, and sensory conditions of work (see Strati, 2010, p. 886) were quite stereotypically associated with certain occupations (see Parviainen, 2014). The sales profession usually features ‘open' working teams to consultants, contrary to financial administration, for example.

\footnotetext{
We try to ensure that the candidate fits the place ... People in financial administration are usually more calm and quiet, so we ensure that the recruited fits there. It doesn't matter if you're talkative, but traits like arrogance don't fit there; I can't send a person like that there if others are humble workers who like to sit in place and work ... You don't have to be similar, but at least something like that. (Timo)
}

The primacy of person-to-person skills in the labor market (e.g., Bailly \& Léné, 2013; Nickson et al., 2003) easily leads one to believe in the inevitable triumph of extraversion. However, as our interviewees explained, one can be too social: a 'piece in a wrong 
place', 'like a fish on dry land', or a 'nightmare', and even 'get fumigated' out of the team. Solving the puzzle, especially in the case of a new client, may demand several 'shots in the dark, because things aren't just black and white but nuances', as Seppo described the challenges of his work. And these nuances can only be captured through one's gut feeling after meeting the client often enough and 'figuring out who their good guy might be'. Participating in the interviews the client company arranges with the shortlist candidates is sometimes necessary to get to know the customer's preferences. Occasionally, however, the professionalism of consultants emerges so that they 'have to know better than the client firm itself what it needs', one consultant explained.

Despite the need to take into account differences in organizational cultures, there is one general change that consultants have noticed regarding the ICT sector: 'even some years ago, concrete, hard know-how was looked for but now ... you need to be more versatile, flexible and adaptable and learn quickly', Jukka explained. He added that a candidate with 'poor social skills is sent nowhere' because all employees have to be ready to work in some capacity in customer service. Other interviewees also unhesitatingly agreed with our tentative proposal of the importance of personality in the current labor market: you have the possibility of reaching the final phase of recruitment if you are formally qualified but, in the end, you may lose your chances for employment because your personality is not a good fit. The idea was crystallized by Hannele's pithy summarization: 'Your CV gets you the job, but your personality loses it.'

\title{
Good vibrations and strange feelings
}

\begin{abstract}
It's the feeling when you interview someone, how they behave, what kind of personality they are, how they go down with you ... It's the impression that you get of the person ... How they would fit the team, how you could work with them.... Quite often the first impression-when you shake hands with them, if something prickles in the back of your head because there's something strange—quite often it's better to follow that. (Jukka)
\end{abstract}

For the recruit candidate, performing a good personality with graceful social skills is about impression management by verbal and nonverbal means; one is expected to 'sell' himself/herself as a promising team-worker and a nice character (cf. Nickson et al., 2003). Our interviewees turned out to stress three major factors in their assessments: the candidate's gestures, appearance, and the authenticity of a personality.

\section{Assessing communication skills by gestures}

The consultant expects to sense the ideal personality through multisensory gestures that are believed to signal it; having a 'solid handshake, look in the eye and the ability to speak fluently', as one consultant crystallized it. The majority of the interviewees, as above cited Jukka, believed in the first impression's inescapable importance when they encounter candidates. He explained that he can immediately 'feel' the candidate's personality and co-operation skills, and that he consciously reflected whether the candidate managed to make a favorable impression on him. A handshake was mentioned as being 
an especially revealing gesture, indicating a certain personality type, and sometimes the wrong one. In Western culture, a 'constant' and 'firm' handshake is strongly associated with openness, mental health, and self-confidence, which self-help books on using body language to impress eagerly assert (e.g., Eggert, 2010, pp. 84-87). Smiling is also always interpreted as a promising sign, and applicants should 'smile' with their voice, too (cf. Koivunen, 2011).

Sometimes, a recruit candidate may generate 'strange feelings' in the consultant, or 'prickling in the back of your head', as above cited Jukka put it-and this feeling the consultants also definitely count on. The feeling was associated with gestures such as 'fiddling with a piece of paper', 'answering with difficulty' or 'sitting hunched over'. The 'wrong' handshake alone does not necessarily matter. Instead, if it is combined with too many gestures directed away from the consultant's body, it makes the consultant feel uncomfortable and suspicious about the candidate's character and social skills.

I don't necessarily pay attention to their way of shaking hands unless there's something really strange, for example if they don't want to shake hands or they reach out their hand but so that I do not come into contact with them ... Of course it's the whole being, how you are. Once there was an interviewee who sat sideways and hardly looked into my eyes during the whole interview. It really leaves a strange feeling with you; what was that? (Tanja)

On the other hand, consultants easily interpret gestures such as 'staring' or 'answers given too quickly' as signs of 'arrogance', 'hostility', and 'impudence', although they no doubt are gestures directed to the consultant's body. This also applies to salesmen, who nevertheless are required to have 'big egos' and perform slightly arrogant gestures. An ideal salesman who closes deals has not only the ability to humbly listen to a customer but also to know the moment when the customer should be pushed toward purchasing.

Diane Coole (2007) writes about corporeal structures and styles, which we 'grasp' when conversing with others. Style is a 'relatively open, aesthetic unity of parts that has existential significance as a particular manner of being-in-the-world'. Style consists of nuances of voice, facial expressions, and detailed gestures that are socially learned and contain limited possibilities for improvising. Sometimes the styles, with their rhythms, match, and sometimes cause friction, generating different affects between the bodies (ibid.). It seems that it is a specific rhythm and directions in talk, sight, and movement, in particular, which matters in the interview in order to generate favorable affects in the consultant. In recruitment interviews, it is always the consultants' embodied styles and rhythms in communication and affective feelings and reactions that matter in the end.

There are no specific educational requirements for becoming qualified as a recruitment consultant. Rather, as was the case with our interviewees, varying backgrounds in education and working life are typical. Many interviewees emphasized their unique life histories and personalities as critical factors in their professional skills. Timo, for example, had actively been engaged in sports. He explained that his identity has been thoroughly built through competitive sports: 'I'm purely just an athlete ... that's what I am, it all comes from there,' he explained, referring to his ability to 'smell' the potential recruits even without necessarily talking with the candidate at all. Timo emphasized being a 'very emotional person' which he accounted for with his sports background, and that he feels favorable affects when sensing 'emotional openness' in a candidate. He also 
admitted that if a candidate has played as a team captain, for example, 'it sure looks good on the CV or sounds good in the interview'.

A few interviewees had also pondered how their own personalities and interests influence their judgments of the candidates' personalities. For Kari, it was evident that his former career in military recruitment and experience in interviewing hundreds of soldiers clearly affected his selection criteria.

If I interview some old soldier who has gone to cadet school, I think he's upright and good even though I try not to ... Surely your background always influences you; if anyone says otherwise, they're lying. I guess it's a subconscious thing ... It makes you the human being you are.

Other interviewees also said they believe that sports are an excellent ground for learning management skills, social co-operation, and losing graciously. Therefore, it is possible that if the consultant comes to know that the candidate is active in sports, she/he may begin to interpret the interviewee's gestures as indicating 'good' social skills. Or, perhaps, if both the candidate and the consultant happen to be athletes or soldiers, for example, they simply speak more or less the same body language, which makes the consultant feel 'at home' with the interviewee. Consultants' respect for experience in the military and (team) sports can be expected to favor male candidates, especially in countries like Finland, where national service, meaning mainly military service, is mandatory for men. In their study of headhunters, Susan Meriläinen and her colleagues (2013, p. 12) found that even the branch of military service matters when recruiting executives: 'Everybody wants that really good guy who has completed officer training in the guerrilla forces,' one male interviewee explained.

In some accounts, however, social skills were feminized. Kari, for example, explained that in the male-dominated ICT field, being a woman may be an advantage itself because some employers associate femaleness with fluid social skills. This kind of essentialization of gender (cf. Peterson, 2010) also turned out to permeate the psychological tests used in recruitment, which have different scales for male and female candidates in social and emotional skills. In client service, Kari believed female workers act as 'bumpers' who do not get as much 'mud' on themselves as male workers. Therefore, he sometimes envisages how the female candidates he has picked for the shortlist go and 'charm' their clients, which we interpret as probable (hetero)sexualization of female employees (e.g., Brower, 2013; Caven et al., 2013).

\section{Making judgments about appearance}

Seppo explained that one particularly 'hygienic' difference between job applicants is appearance, which 'should basically not matter'. He, like some other consultants, on the one hand, denied to put emphasis on appearance, but, on the other hand, admitted that it may matter in the recruitment. In any event, they emphasized that they feel confident about a candidate who looks in line with the vacancy to be filled in terms of dress, make-up, hair-style, and jewelry (cf. Dean, 2005; Dellinger \& Williams, 1997). If a blue-collar job applicant is dressed in a suit, or a candidate interested in a white-collar job is dressed in a sweatshirt, it puzzles the consultant. 'Neutrality' and 'tidiness' were

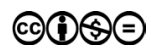


always mentioned as positive signs. Employees are in any case the 'business cards' and 'representatives of the company's brand', the interviewees pointed out.

Consultants spontaneously listed several details that potentially bothered them about the candidates' appearance: visible tattoos, piercings, overweight, bohemian hairstyle, punk style, nose jewelry, boldness, bad skin disease, and 'general slovenliness'. All interviewees agreed with our tentative claim that a female applicant with 'revealing' clothes would be interpreted as an implausible choice. On the other hand, Timo had noted that women tend to dress up for the interview more carefully than men. This is not surprising, for women's investment in their appearance is taken for granted in the labor market (Adkins \& Lury, 1999; Dean, 2005).

Our interviewees also valued leisure sport activities regarding the appearance of a candidate, which reflects the overall importance of fitness in the current culture. The trained, lean body is axiomatically associated with beauty and health, and it gives an impression of discipline, capability, strength, and endurance (e.g., Bordo, 1993). Interviewees pointed out that fitness correlates with sick leaves, which they have to keep in mind when shortlisting. Particularly, if there are many applicants for a vacancy who in fact possess formal competencies, candidates perceived as 'overweight' or 'flabby' may be disqualified. Tuula expressed her awareness of the outlook that sometimes she is 'forced to think' whether the client 'appreciates a certain kind of appearance'.

In ICT consulting, the 'top performer' is also often associated with a variety of skills and attributes that are characterized as somewhat masculine (Joshi \& Kuhn, 2007). Regarding the appearance, our interviewees interestingly named the (male-dominated) ICT sector as a special case where employees can be 'more personal' and 'more yourself', and where they 'have to overlook a few things'. In 'distinctive' and 'garish' cases, consultants feel better if they 'warn' the client beforehand in order to 'prepare them for the first shock'. The consultant may nevertheless feel that the 'weird' guy has a superb personality and the best know-how for a position.

\section{Testing the authenticity of a personality}

Sometimes, consultants associate a strange feeling with a fictitious personality. Some seemed to understand the interview as a test where the candidate's real know-how and personality inescapably become revealed. Seppo said that 'things aren't always the way people tell us ... and our job is to find out what is true by legal means' (cf. Koivunen et al., 2015, p. 10). Kaisa's strategy is to 'mill deeper under the surface' by surprising the candidate with extra questions, and if the candidate 'stiffens', 'looks around', or demonstrates 'some other tiny things that are very difficult to explain', it means they are lying. She also tests the genuineness of an applicant's personality by asking the reception workers of the company about how the candidate behaved when entering the office. Kari explained that the façade can be penetrated with questions. Details in the candidate's behavior are observed very carefully to reveal bluffing, as in poker, Timo added.

However, some consultants, particularly female ones, said they believe that the interview situation per se influences the candidate's performance. Tanja related that young candidates, in particular, are sometimes so nervous that they are 'very serious, drops on the forehead, hands sweating', while men 'conceal their nervousness by joking'. Therefore, she, like other female consultants, explained that she consciously tries to 
calm down and support nervous candidates by creating a relaxing atmosphere. Hannele described how she tries to avoid a 'Gestapo-style' interrogation. Sometimes, consultants overlook the peculiar behavior of young interviewees, such as answering a mobile phone in the middle of an interview, because they seemingly do not fully understand the purpose of the recruitment interview. On the other hand, some female consultants admitted that their gender and age may be a reason why older male candidates, with long work experience, sometimes do not take them very seriously, which accordingly can affect an assessment of the candidate's dubious personality. However, both male and female consultants believed that you either have or do not have a good personality.

You can develop skills and develop experience, but there's nothing you can do about chemistry and personality ... You can't change a person and it is not something that the work community is willing to do ... In terms of personality, you're expected to be a completely finished package. (Hannele)

Consultants tended to believe that they cannot really be 'cheated' in the interview regarding the candidate's personality. However, despite the consultant's careful sensing and testing, the puzzle they have completed sometimes breaks down when the candidate, to the consultant's surprise, performs differently in the client company's interview. 'For God's sake I can't always know, although in most cases I can,' Seppo stated regarding the reliability of his gut feeling. We suggest that surprises reflect the fluidity and situationality of affects depending on the specificity of encountering bodies (Seyfert, 2012) and their characteristic styles.

\section{Discussion: Searching for riskless bodies}

This article has discussed how Finnish recruitment consultants work in order to find suitable employees for clients who have requested that they select the shortlist candidates in single assignments. The pressure to find the 'right' personalities to strengthen customer service and working teams has made staffing decisions critical for companies and public organizations, and outsourcing of the recruitment process is implemented globally to save costs and improve the quality of recruitment (Jamil \& Neem, 2013; Ordanini \& Silvestri, 2008). Our analysis concerned the embodied know-how that the recruitment agencies sell to their client companies in order to fulfill their expectations. First, we addressed how consultants observed their clients in order to find out their specific needs. Of central interest was the recruitment interviews that the consultants arrange with the candidates that seem most promising based on their CVs. We described how consultants 'read' the applicants' personalities, that is, professional competencies, through their behaviors and gestures in the interviews. Although the discussion has been slightly focused on the ICT business, it has nevertheless concerned consultants' working practices and judgment criteria-which we considered interconnected-on a more general level.

Our theoretical framework was based on organizational decision-making models that have already recognized the central role of emotions, moods, and affects in making judgments. We applied in particular Dane and Pratt's (2007) conception of intuition as a nonconscious process that involves rapidly produced holistic associations that result 
in affectively charged judgments. Relying on 'gut feelings' and 'instincts', the affective decision-making of recruitment consulting can be seen as a form of the intuitive working process. We claimed that the consultants' judgments about employee candidates' social skills, professional competences or how their personalities might 'fit' into different working environments are eventually justified by affective resonances in the consultants' bodies. To better understand the process of intuition, of which affects are an integral part, we suggested that the term 'affect' must be considered in its corporeal and socio-cultural contexts instead of decision makers' mental, cognitive, and physiological processes. ADM is not co-incidental or solely subjective but inter-corporeal, social, and cultural by its nature.

Recruitment was approached as a profoundly embodied process where bodysubjects communicate through their own pasts and cultural discourses, making the encountering bodies meaningful to each other. We claimed that consultants' working methods are based on strategic feeling and sensing people, places, and atmospheres throughout the recruitment process to secure the best 'organization-person fit'. Our study illuminated how consultants map the stimuli they sense when visiting the client companies and the affects those stimuli generate. Working teams, places, organizational cultures, and occupations were categorized as either 'open and bold' or 'closed and quiet', for example, and a new employee's personality was expected to fit into it. Although the consultants emphasized their clients' individual needs, it was evident that nowadays employers search for flexibility, adaptability, and fluent social skills.

We described how consultants assess an applicant's personality by paying attention to bodily gestures and rhythms that are believed to indicate social skills and good personality. Candidates' multisensory bodily gestures and details of their appearance generate different kinds of affects, such as 'good vibrations' or 'strange feelings' in the consultants shaping the ground for their decision-making. In the recruitment interviews, consultants were engaged in observing job applicants' micro-movements, and simultaneously listening to their bodily responses and affective impulses toward applicants in order to secure the 'authenticity' of their personalities. By referring to Coole's (2007, pp. 426-427) discussion of an embodied style as 'forged and sedimented within intersubjective life-worlds', we regarded the interview as an encounter of specific corporeal styles and rhythms that are formed through the body's lived past. We discussed how the consultants' own values and interests may affect their decision-making. Although consultants were conscious of it and experienced it as strength in their work, it is possible that they do not fully recognize the outcomes of their subjectivity. It seemed that applicants' personalities were quite straightforwardly naturalized by their embodied styles of speaking, touching, moving, and looking, in particular.

In making decisions, consultants were sensitive if some bodily attributes of recruit candidates contain potential 'risks'. Recruitment companies usually offer some kind of 'satisfaction guaranteed' contract, which means that pre-recruitment is performed for free or at half-price. This means that risks are not willingly taken, as we claim. Rather, recruitment consulting is based on counting on stereotypical performances and representations of the ideal working body in order to close the recruitment. Therefore, consultants feel obliged to calculate and optimize the outcome and value of their choices, following patterns traditionally linked more to rational decision-making (e.g., Rubinstein, 1998) rather than ADM (see Bracha \& Brown, 2009). However, our study indicates how these previously separated decision-making patterns operate in concert 
and interact contingently. Affects and values are integrated into, rather than separate from, our reasoning processes, and vice versa (e.g., Bracha \& Brown, 2009; Lakomski \& Evers, 2010).

Behind single assignments, it is important to see recruitment consultants as powerful agents who also count on their own preferences. Job seekers with minor neurological problems, such as persons with Asperger syndrome, or shy people can easily be interpreted as 'suspicious personalities', since they may have great difficulties in retaining the proper eye contact in interview situations. It should also be critically examined how this type of ADM in recruitment consulting that looks for the 'riskless bodies' excludes bodies of certain ages, genders, ethnicities, and sexualities. Further, it is worth asking what kind of new hierarchies in the labor market are developing between different job candidates regarding their 'personality types'. Working as gatekeepers for the labor market, recruitment consultants (and headhunters) do not just follow the expectations of their client companies. Their role is more influential and transformative: they also determinate what type of people get through the gate.

\section{References}

Adkins, L. and Lury, C. (1999) The Labour of Identity: Performing Identities, Performing Economies. Economy \& Society 28(4): 598-614. doi: http://doi. org/10.1080/03085149900000020.

Adkins, L. (1992) Sexual work and the employment of women in the service industries. In Savage, M. and Witz, A. (eds) Gender and Bureaucracy. Oxford: Basil Blackwell, 207-228. doi: http://doi.org/10.1111/j.1467-954X.1991.tb03361.x.

Agor, W.A. (1989) Intuition in Organizations: Leading and Managing Productively. Newbury Park, CA: Sage. doi: http://doi.org/10.1002/bdm.3960070308.

Ahmed, S. (2004) Cultural Politics of Emotion. Edinburgh: Edinburgh University Press. doi: http://doi.org/10.1177/1464700106069051.

Bailly, F. and Léné, A. (2013) The Personification of the Service Labour Process and the Rise of Soft Skills: A French Case Study. Employee Relations 35(1): 79-97. doi: http://doi. org/10.1108/01425451311279429.

Behling, O. \& Eckel, N.L. (1991) Making Sense out of Intuition. Academy of Management Executive 5(1): 46-54. doi: http://doi.org/10.5465/AME.1991.4274718.

Blackmann, L. and Venn, C. (2010) Affect. Body \& Society 16(1): 7-28. doi: http://doi. org/10.1177/1357034X09354769.

Bordo,S.(1993)Unbearable Weight:Feminism, Western Culture, and the Body.Berkeley:University of California Press. doi: http://doi.org/10.1002/(SICI)1099-1298(199911/12)9:6<481::AIDCASP546>3.0.CO;2-2.

Bracha, A. and Brown, D.J. (2009) Affective Decision Making: A Behavioral Theory of Choice. Paper provided by Cowles Foundation for Research in Economics, Yale University in its series Cowles Foundation Discussion Papers with number 1633. http://cowles. yale.edu/sites/default/files/files/pub/d16/d1633.pdf.

Brower, T. (2013) What's in the Closet: Dress and Appearance Codes and Lessons from Sexual orientation. Equality, Diversity and Inclusion: An International Journal 32(5): 491-502. doi: http://doi.org/10.1108/EDI-02-2013-0006.

Burke, L.A. and Miller, M.K. (1999) Taking the Mystery out of Intuitive Decision Making. Academy of Management Executive 13(4): 91-99. doi: http://doi.org/10.5465/ AME.1999.2570557. 
Caven, V., Lawley, S. and Baker, J. (2013) Performance, Gender and Sexualised Work. Beyond Management Control, beyond Legislation? A case Study of Work in a Recruitment Company. Equality, Diversity and Inclusion: An International Journal 32(5): 475-490. doi: http://doi.org/10.1108/EDI-08-2011-0051.

Combs, G., Milosevic, I., Jeung, W. and Griffith, J. (2012) Ethnic Identity and Job Attribute Preferences: The Role of Collectivism and Psychological Capital. Journal of Leadership \& Organizational Studies 19(1): 5-16. doi: http://doi.org/10.1177/1548051811433359.

Coole, D. (2007) Experiencing Discourse: Corporeal Communicators and the Embodiment of Power. BJPIR 9(3): 413-433. doi: http://doi.org/10.1111/j.1467-856X.2006.00258.x.

Dane, E and Pratt, M. (2007) Exploring Intuition and Its Role in Managerial Decision Making. Academy of Management Review 32: 33-54. doi: http://doi.org/10.5465/ AMR.2007.23463682.

Daniels, K. (2008) Affect and Information Process. In Hodgkinson, G.P. and Starbuck, W.H. (eds.) The Oxford Handbook of Organizational Decision Making. Oxford: Oxford University Press, 325-241. doi: http://doi.org/10.1093/oxfordhb/9780199290468.003.0001.

Dean, D. (2005) 'Recruiting a Self: Women Performers and Aesthetic Labour. Work, Employment and Society 19(4): 761-774. doi: http://doi.org/10.1177/0950017005058061.

Dellinger, K. and Williams, C.L. (1997) 'Makeup at Work': Negotiating Appearance Rules in the Workplace. Gender \& Society 11(2): 151-177. doi: http://doi. org/10.1177/089124397011002002.

Downey, L.A., Lee, B. and Stough, C. (2011) Recruitment Consultant Revenue: Relationships with IQ, Personality, and Emotional Intelligence. International Journal of Selection and Assessment 19(3): 280-286. doi: http://doi.org/10.1111/j.1468-2389.2011.00557.x.

Eggert, M.A. (2010) Brilliant Body Language. Impress, Persuade and Succeed with the Power of Body. New Jersey: FTPress.

Elo, S. and Kyngäs, H. (2008) The qualitative content analysis process. Journal of Advanced Nursing 62(1): 107-15. doi: http://doi.org/10.1111/j.1365-2648.2007.04569.x.

Finlay, W. and Coverdill, J.E. (2000) Risk, Opportunism, and Structural Holes. Work and Occupations 27(3): 377-405. doi: http://doi.org/10.1177/0730888400027003006.

Gardner, W.L., Reithel, B.J., Cogliser, C., Walumbwa, F.O. and Foley, R.T. (2012) Matching Personality and Organizational Culture: Effects of Recruitment Strategy and the Five-Factor Model on Subjective Person-Organization Fit. Management Communication Quarterly 26(1): 585-622. doi: http://doi.org/10.1177/0893318912450663.

Gorton, K. (2007) Theorizing Emotion and Affect: Feminist Engagements. Feminist Theory 8(3): 333-348. doi: http://doi.org/10.1177/1464700107082369.

Halford, S., Savage, M. and Witz, A. (1997) Gender, Careers and Organisation. London: MacMillan. doi: http://doi.org/10.1007/978-1-349-25562-7.

Hayashi, A.M. (2001) When to Trust Your Gut. Harvard Business Review 79(2): 59-65.

Headland, T.N., Pike, K. and Harris, M. (eds.) (1990) Emics and Etics: The Insider/ Outsider Debate. Ser. Frontiers of Anthropology/book 7. doi: http://doi.org/10.1525/ aa.1992.94.1.02a00250.

Hemmings, C. (2005) Invoking Affect: Cultural Theory and the Ontological Turn. Cultural Studies 19(5): 548-567. doi: http://doi.org/1080/09502380500365473.

Hodgkinson, G.P. and Starbuck, W.H. (eds.) (2008) The Oxford Handbook Of Organizational Decision Making. Oxford: Oxford University Press. doi: http://doi. org/10.1177/0170840613483966.

Hofbauer, J. (2000) Bodies in a Landscape: On Office Design and Organization. In Hassard, J., Holliday, R. and Willmott, H. (eds.) Body and Organization. London: Sage, 166-191. doi: http://doi.org/10.4135/9781446218303.n9.

Hofstede, G. (1997) Culture and Organizations: Software of the Mind. New York: McGrawHill. doi: http://dx.doi.org/10.1080/00208825.1980.11656300. 
Holstein, J.F. and Gubrium, J.A. (1997) Active Interviewing. In Silverman, D. (ed.) Qualitative Research: Theory, Method and Practice, London: Sage, 113-129. doi: http://doi. org/10.4135/9781412986120.

Hsieh, H-F. and Shannon, S.E. (2005) Three Approaches to Qualitative Content Analysis.Qualitative Health Research 15(9): 1277-1288. doi: http://doi. org/10.1177/1049732305276687.

Humle, D.M. (2014) The Ambiguity of Work: Work Practice Stories of Meaningful and Demanding Consultancy Work. Nordic Journal of Working Life Studies 4(1): 119-137. doi: http://doi.org/10.19154/njwls.v4i1.3555.

Jamil, R. \& Neem, H. (2013) The Impact of Outsourcing External Recruitment Process on the Employee Commitment and Loyalty: Empirical Evidence from the Telecommunication Sector of Pakistan. Journal of Business and Management 8(2): 69-75. doi: http://doi. org/10.9790/487X-0826975.

Joshi, K.D. and Kuhn, K.M. (2007) What it Takes to Succeed in Information Technology Consulting: Exploring the Gender Typing of Critical Attributes. Information Technology \& People 20(4): 400-424. doi: http://doi.org/10.1108/09593840710839815.

Junnila, K. and Honkaniemi, L. (2010) Organisaatioiden rekrytointikäytännöt. [Recruiting Practices in Organizations.] Helsinki: Työterveyslaitos. doi: http://doi.org/10.1080/136 39080.2014.934788.

Kadefors, R. and Hanse J.J. (2012) Employer's Attitude toward Older Workers and Obstacles and Opportunities for Older Unemployed to Re-enter Working Life. Nordic Journal of Working Life Studies 2(3): 29-47. doi: http://doi.org/10.19154/njwls.v2i3.2362.

Khatri, N. and Ng, H.A. (2000) The Role of Intuition in Strategic Decision Making. Human Relations 53(1): 57-86. doi: http://doi.org/10.1177/0018726700531004.

Kinnunen, T. (2010) 'A Second Youth': Pursuing Happiness and Respectability through Cosmetic Surgery in Finland. Sociology of Health \& Illness 32(2): 258-271. doi: http://doi. org/10.1111/j.1467-9566.2009.01215.x.

Koivunen, T. (2011) Gender in Call Centre Work. Tampere: Tampere University Press.

Koivunen, T., Ylöstalo, H. and Otonkorpi-Lehtoranta, K. (2015) Informal Practices of Inequality in Recruitment in Finland. Nordic Journal of Working Life Studies 5(3): 3-21. doi: http://doi.org/10.19154/njwls.v5i3.4804.

Koski, A. (2013) Reclassifying the Finnish ICT Experts in the Big Picture: From the Tribe of the Chosen to Waiting for the Other Shoe to Drop. Unpublished paper for the $8^{\text {th }}$ International Conference in Critical Management Studies, University of Manchester $10^{\text {th }}-12^{\text {th }}$ July.

Kvale, S. (1996) Interviews. London: Sage. doi: http://doi.org/10.4135/9781849208963.

Kyrölä, K. (2010) The Weight of Images. Affective Engagement with Fat Corporeality. Turku: University of Turku.

Lakomski, G. and Evers, C.W. (2010) Passionate Rationalism: the Role of Emotion in Decision Making. Journal of Educational Administration 48(4): 438 - 450. doi: http://doi. org/10.1108/09578231011054707.

Legard, R., Keegan, J. and Ward, K. (2003) In-depth Interviews. In Ritchie, J. and Lewis, J. (eds.) Qualitative Research Practice. London: Sage, 138-169.

Loretto, W. and White, P. (2006) Employers' Attitudes, Practices and Policies towards Older Workers. Human Resource Management 16(3): 313-330. doi: http://doi.org/10.1111/ j.1748-8583.2006.00013.x.

Meriläinen, S., Tienari, J. and Valtonen, A. (2013) Headhunters and the 'Ideal' Executive Body. Organization 22(1): 3-22. doi: http://doi.org/10.1177/1350508413496578.

Nickson, D., Warhurst, C., Witz, A and Cullen, A-M. (2001) The Importance of Being Aesthetic: Work, Employment and Service Organization. In Sturdy, A., Grugulis, I. and Willmott, H. (eds.) Customer Service: Empowerment and Entrapment. Houndmills: Palgrave, 170-190. doi: http://dx.doi.org/10.1108/03090560610681069. 
Nickson, D., Warhurst, C., Cullen s.M. and Watt, A. (2003) Bringing in the Excluded? Aesthetic Labor, Skills and Training in the 'New' Economy'. Journal of Education and Work 16(2): 185-203. doi: http://doi.org/10.1080/13639080305560.

Nilsson, K. (2011) Attitudes of Managers and Older Employees to Each Other and the Effects on the Decision to Extend Working Life. In Ennals, R. and Salomon, R.H. (eds.) Older Workers in a Sustainable Society. Frankfurt am Main: Peter Lang, 147-156.

Ordanini, A. and Silvestri, G. (2008) Recruitment and Selection Services: Efficiency and Competitive Reasons in the Outsourcing of HR Practices. The International Journal of Human Costing and Accounting 13(4): 273-293. doi: http://doi.org/10.1080/09585190701799960.

Parviainen, J. (2014) The Performativity of 'Double Bodies': Exploring the Phenomenological Conception of Leib/Körper Distinction in Interactive Bodywork. The International Journal of Work Organisation and Emotion 6(4): 311-326. doi: http://doi.org/10.1504/ IJWOE.2014.068031.

Peterson, H. (2010) The Gendered Construction of Technical Self-Confidence: Women's Negotiated Positions in Male-dominated, Technical Work Settings. International Journal of Gender, Science and Technology 2(1): 65-88.

Probyn, E. (2004) Teaching Bodies: Affects in the Classroom. Body \& Society 10(4): 21-43. doi: http://doi.org/10.1177/1357034X04047854.

Rubinstein, A. (1998) Modeling Bounded Rationality. Cambridge, MA: The MIT Press. doi: http://doi.org/10.2307/1060679.

Sadler-Smith, E. and Sparrow, P.R. (2008) Intuition in Organizational Decision Making. In Hodgkinson, G.P. and Starbuck, W.H. (eds.) The Oxford Handbook of Organizational Decision Making. Oxford: Oxford University Press, 305-324. doi: http://doi. org/10.1093/oxfordhb/9780199290468.003.0016.

Seyfert, R. (2012) Beyond Personal Feelings and Collective Emotions: Toward a Theory of Social Affect. Theory, Culture \& Society 29(6): 27-46. doi: http://doi. org/10.1177/0263276412438591.

Shapiro, S. \& Spence, M.T. (1997) Managerial Intuition: A Conceptual and Operational Framework. Business Horizons 40(1): 63-68. doi: http://doi.org/10.1016/S0007-6813(97)90027-6.

Strati, A. (2010) Aesthetic Understanding of Work and Organizational Life: Approaches and Research Developments. Sociology Compass 4(10): 880-893. doi: http://doi. org/10.1111/j.1751-9020.2010.00323.x.

Tienari, J., Meriläinen, S., Holgersson, C. and Bendl, R. (2013) And Then There Are None: On the Exclusion of Women in Processes of Executive Search. Gender in Management: An International Journal 28(1): 43-62. doi: http://doi.org/10.1108/17542411311301565.

Tipper, J. (2004) How to Increase Diversity through Your Recruitment Practices. Industrial and Commercial Training 36(4): 158-161. doi: http://doi.org/10.1108/00197850410542392.

Weick, K. E. 1995. Sensemaking in Organizations. Thousand Oaks, CA: Sage. doi: http://doi. org/10.1002/hrdq.3920090211.

Wetherell, M. (2012) Affect and Emotion. A New Social Science Understanding. Los Angeles: Sage. doi: http://doi.org/10.1177/1350506814552785b.

\section{Note}

${ }^{1}$ Here, we report some outcomes from the research project 'The Working Body in the Postindustrial Economy' (WORKBOD) financed by the Academy of Finland in 2011-2014. Our interest in ICT workers stemmed from the situation following the fall of Nokia, on which the country's economy had been strongly dependent from the early 1990s until the mid-2010s. More and more engineers were soon unemployed; some of them started their own businesses or found a new job on their own, while others registered in recruitment companies' files. 